\title{
A Brief Analysis of the Resurrection Theme in Ming Bao Ji
}

\author{
$\mathrm{Pu}$ Huajun \\ Office of Sichuan University for Nationalities \\ Sichuan, Kangding, 626001, China
}

\begin{abstract}
Ming Bao Ji which mainly promotes the Buddhist doctrine is a supernatural tales with lots of resurrection theme. The novel narrates the stories which people can be alive after death. It contains the meaning of transmutation and newborn. This resurrection theme novels reflect the Tang people's pondering on the ways of nature and man and the life noumenon and the best wishes about persuading people of the world to be good. It also presents with its unique circular structure the concept of the novel about Tang people's curiosity with care and going towards the ode. And it becomes the advocate of the later classical novels with the theme of the resurrection.
\end{abstract}

Keywords- the Resurrection, the Theme, the Soul, the Circular Structure

\section{INTRODUCTION}

Ming Bao Ji which is written by $\mathrm{Li}$ Ministry of Personnel in early Tang dynasty Tang Lin is a set of supernatural taless. He said in his preface that he wrote the novels because he admired the famous GuanYin Yingyan Ji, Xuan Yan Ji and Ming Xiang Ji since the Jin dynasty. For this reason he wrote in his preface, "All because we shall ask to make clear of the goodness and evil, admonish people in the future, and make the listeners have deep feeling in their heart, I wrote it. I, Tang Lin, not only admired the style of these works but also consider to persuade people, so I recorded all the things I heard before and made a collection novels for them." It chiefly focuses on recording the efficacious different things of Buddhist to propagate the causality in the Buddhist doctrine. Therefore someone called it "the Buddhist novles" or "a book of Buddhistic teaching". Its works which were mostly compiled in the "Tai Ping Guang Ji” are widespread and has very large impact. After that, Lang Yulin's Ming Bao Shiyi which is written by copying others is the sequel. A special type of novels among the recorded ghost stories in Ming Bao Ji tells us the stories of resurrection. This special type of novels reflects the thinking of life from people in the Tang Danasty and the best wishes about persuading people of the world to be good. At the same time, it also demonstrates the concept of the novel about Tang people's curiosity with care and going towards the ode. And it becomes the advocate of the later classical novels with the theme of the resurrection.

\section{THE DEFINITION OF RESURRECTION}

The resurrection means to be alive after death. The word "resurrection" has its earliest record in Shan Hai Jing. The Hai Wai Xi Jing has recorded, "When Xingtian and the
Emperor came here to contend for God, the Emperor cut off his head and buried it on the mountain of Changyang. Xingtian treated his breast as eyes and his belly button as mouth to fight with Ganqi dance." Because Xingtian's fighting will didn't slack off, even if he was dead, he is still alive. After he was cut off his head, he treated his breast as eyes and his belly button as mouth to continue to fight with the arms in his hands. For this reason, he is regarded as the God of war. The Xiandi Ji in Hou Han Shu has recorded, "Someone in Changsha was dead. But after several months, he was alive." The fifteenth volume of Sou Shen Ji written by Gan Bao in the Jin Dynasty is an article with the name " There are men and women in HeJian county". It tells that a woman in HeJian county has moved the Heaven and the Earth because of her absolute sincerity, and finally she has gotten her life back after death. Another article with the name "Yan Ji in Lagya" also tells the story about Yan Ji's resurrection. The second Volume of Guangyang Zaji written by Liu Xianting in Qing Dynasty has recorded, "The green pines besides the bridge has drooped which tells us it had been dead before. But now it has been half alive. The ancient people always consider the things about resurrection as the mysterious things with the main performance for their curiosity and awe of the mysterious power. The Seventh Year of Zhaogoang in Zuozhuan has recorded," Life begins to change from the spirit, namely producing the sprit. Yang is called the soul. If you use the objects finely and excessively, and the soul will be strong." Another record in the Twenty-fifth Year of Zhaogong has said, "The essence of the heart is the soul. When the soul has gone, how can the life endure long time?" The ancients believe that life is composed by the coordination of yin and Yang. Both of them can't be separated with each other. So we consider the soul as the gas of Yang which is the mind, spirit and mind of human. We consider the spirit as the gas of Yin which is the feeling of human body. When a human is dead and his soul is back to the heaven. The gas of Yang which represents the thinking and spirit is separated from the sprite which represents the body. So the gas of Yin is back to the underground. The soul is the master of life, controlling human mental activities. As long as the soul of human is still there, human can get back to life even if the external form of body is dead. The article" There are men and women in HeJian county" in Sou Shen Ji is like this. And the Du Liniang in Mudan Ting is like this too.

The Swiss psychologist Karl Gustav Carl Jung makes such a definition about the word "resurrection" in the book of the archetypes and the collective unconsciousness, " This means that the rebuilt after the death of human's existence." 
A new element which indicates the change, evolution and transformation of existence goes into this place. This change may be either the change in essence which means that the resurrection of people are different, or the insubstantial change which means that only the existence of the general situation has changed. The situation is like the situation that a person finds himself in different locations or in the different body structure. It may be the changes of the body just like the Christians have thought that the body can be alive. Speaking at a higher level, the process can not be understood with the overall sense of the material: people believe that the resurrection of the dead is the glorified "regeneration of the body"(corpus giorificationis) and the ascension of the body of the soul (subtle body) is in a state of immortality. Obviously, Carl Jung believes that the resurrection means change. The resurrection is not only the vital signs of the resurrection which makes the body with vitality again, but also means the higher level of change in sprite and thinking which indicates a new beginning and a clean break with the former thing.

\section{THE OVERVIEW OF THE STORIES OF THE RESURRECTION IN MING BAO JI}

Ming Bao Ji in the ancient novel periodicals which is edited and proofreaded by Fang Shiming has been printed and published by Zhonghua Book Company is divided into three volumes, namely the upper, middle and lower volume. There are 53 edited articles and 15 articles as the addendum in the book. It has collected 68 pieces of works in total in the book. The works which involve the resurrection are Sun Bao, Daye Keseng, Zhengshi Bian, Li Shanlong, Zhou Wudi, Shiren Liang, Zhang Gongjin, Kong Ke, Wang Shu, Zhang Fayi, Liu Zhigan, Zhao Wenxin, Yanzhou Ren, Yang Shichao, Zhao Wenruo, Dunqiu Lizhi, Xie Hongchang Qi and other 16 pieces of works. The narration in Sun Bao is like this, "He died, then in a moment his body got warm. After more than forty days he brought to life." After Sun Bao brought to life, he told the story with details about his experience of the hell. The works of Li Shanlong gave us a story like this: Li Shanlong suddenly died because of sudden ill. But a place like the size of palm in his heart is still warm. His family didn't have the heart to hold a funeral procession and bury him. On the seventh day he unexpectedly raised from the dead. After his resurrection he told his family the story about his experience of the hell. This kind of novels have a common plot model: Someone died suddenly, but his soul left his body. He suddenly appeared in person or led by the officials in the hell who enchanted his soul to the hell to witness the wicked in hell got all kinds of cruel torture. After that because he once did many good things with mercy or helped by nice people, his soul got back to human's world. In other words, he revived after his soul got back his body. The revived man told his experience of the hell to his relatives and friends and persuaded others to believe in Buddhism. And he kept the faith in the worship of Buddha. The works of Zhou Wudi gave us a story like this: The Emperor Wu in Zhou Dynasty likes eating chicken eggs. And he can eat several ones once. The Supervisor board of the royal food who often provides food to him was in the prison to see the following scene. There were dozens of jailers who all have the head of a cow and the body of a human in an iron bed. The emperor had been on the bed, the gaolers detained him with the iron girders. The ribs of the emperor is broken. And the chicken were all got out from the broken place.

In a moment a lot of chicken which can be more than ten hu were the same height with the bed. They are the chicken who beg for their lives from the emperor. After the death of your nine five supreme emperor, he inevitably suffered such harsh criminal law. When the Supervisor board of the royal food was leaving, the emperor told the following words, "I heard that the emperor in Sui Dynasty who once had worked with me had the warehouse, jade and silk which were also stored by me. I suffered a lot because I destroyed the Buddhist doctrine as an emperor. And if I was not this could be my merits and virtues. After that there was a saying which is the emperor Wen gave his orders to make people in the world to collect money to get blessing. The author presents the stories like this to his readers which doubtlessly has strong persuasion. The travel to the hell after death and having the enlightenment of the Buddha after waking up have the connotation of the traditional which still showed "The Instructing according to Sacred Way" and the narrative strategy of "Teaching people from the God". Many people who have been brought from death to life changed the past feelings and began to devote themselves to the Buddha. From the point of view of the narrative theme, this contained the meaning of transformation, rebirth and others.

\section{The Structure OF THE "ResURReCtion" IN MING $B A O J I$}

The process of the structure is "we organize the order and consider its weight, run through the nadis and perfect its state so that we can form a complete and precise language life." " He goes beyond the specific text. While it contains the author's understanding of the world, life and art among the narrative units expressed in the text or beyond the narrative units. The structure has has important significance to spy out the biggest implicit meaning of works given by the narrator. The novels with the resurrection theme in Ming Bao Ji mostly have recorded " the things which are suffered, heard and seen by people have their reasons". Even some scholars believe that "the author had a clear purpose and made a series of conscious interviews to finish it." It is "oral history works mode with rigorous style in Tang Dynasty". Scholes and Kellogg once divided the narrative types into experiential narrative and fictional narrative. And they thought that the experiential narrative is loyal to the reality with the true performance; The fictional narrative is loyal to the ideal with the performance of the beauty and goodness. While novels are the recombination of experiential and fictional narrative. The tellers of the stories try to create more convincing stories. They prove the truth and reliability of the occurrence of the stories with all kinds of testimony of the witness and 
physical evidences to try to undermine the non-logic of the plot and dispel the doubt of the audience. But the result is not the truth instead of fiction. It is only a fiction with more clever disguise. At the back of the clever fiction, the resurrection theme in Ming Bao Ji presents the circular structure.

Yang Yi said in the study of the sum total of the novel narrative during two thousand of China in the Historical Theory of Chinese Classical Novels, "The circular thinking is a kind of fusion of the rational and irrational savvy intuition. It commands all-embracing things, but it is beyond all-embracing things. It directly refers to the root of the change about all the things with the free and easy mental state.

He believes that "the logical starting point of Chinese narrative and the operating program with fatalism connect with this wonderful 'circle'. And he also believes that the circular structure with the generalization of all things must deeply penetrate into the poetic wisdom of Chinese people. He can't help making the deep structure of cultural psychology project into the hidden circular structure. The ancients believe that the world is a cycle of Yin and Yang and a man's life is composed of Yin and Yang. There are circular rings in many wonderful realms of Buddhism, such as harmony, completeness, wonderful round and parinirvana, etc. The novels about the resurrection in Ming Bao Ji often present the circular structure of "reality-dreamworld-reality". When the revived people wake up and get back to the reality, he also shows the circular thinking of "Witnessing the reality-chewing the dreamworld-thinking and changing the reality". The content in Zheng Shibian is the following words, " The solider of the Orient House right prison door Bing Cao Canjun, Zheng Shibian is close to twenties years old. But he died because of strange illness. After three days he brought to life." After he got his resurrection, he told the following story by himself. After the death, Zheng Shibian came to the hell. Because he concentrated on chanting Buddhist scriptures, he was lucky enough to meet a monk to help him return to the human world. Since then he has believed in the Buddha and demanded himself strictly with five disciplines. When he occasionally broke the discipline, he was bound to be punished. For example, he would make his mouth have bad breath because of eating pork. The content in Li Shanlong is the following words,

" The captain of left prison door, Li Shanlong was died because of sudden illness in the year of Wude. But the palm place of his heart didn't get cold. His family didn't have the hear to hold a funeral and bury him. At the seventh day he revived." After he got his resurrection, he told the following story by himself. After the death, Li Shanlong was arrested by the clerks in the hell and came to the hell. He read $\boldsymbol{F a}$ Hua Jing and Miaofa Lianhua Jing for the king of the hell. And he traveled to the hell to visit all kinds of criminal penalties in different regions. He promised to send the presents to the three envoys in the hell After he got back the human world. This kind of novels all narrated in the following way. The narrator in reality is dead. And then he went to the hell. What he saw, heard and experienced in the hell have impact on his behaviors after his resurrection. For example, Zheng Shibian who usually doesn't cultivate for blessings gets five disciplines in the hell. After his resurrection, he begins to believe in the Buddha and demand himself strictly with five disciplines. He has finished the resurrection from the spirit to the behavior. The illusory world of the hell affects the real world. And the the real world proved illusory world. So the exact and smooth circular structure is thus formed. Focusing on the narrative of the fictional world reflects the narrative strategy, " Tang people have the meaning of curiosity, and write down the fictional stories by the novels.

The circular structure in Ming Bao Ji puts people in the universe of the heaven and the earth. It implies the way of heaven and human by describing the unique experience from life to death, and death to resurrection. This accords with latent thinking of the ancients with the alternation of Yin and Yang and the situation of mutual containing transfer. This can make the plot of the novels more colorful. The cross collocation in real space and virtual space of the novel text is a good solution to the the narrator's role problem of "action element" which makes it walk between the falsely or truly. When it experiences a diachronism and collocation of the space, so as it can realize the perfect space transfer and make up the integrity of the space structure of novels. There are differences in the density degree of real and illusory space. The narrator always gives brief narration in the way of a few words. This is called "thinness". The narrator gives more narration in details about the experience of traveling the hell. This is called "thickness". A thinness and a thickness, a tension and a relaxation, the connection and changes of the structure, and the proportional allocation reflect the important means in maintaining the narrative rhythm and aesthetic balance. This is strong proof for the novels of Tang people to go towards the ode.

\section{CONCLUSION}

Seen from the type of the novel, Ming Bao Ji is still not completely out of the vestige of the novels in the six dynasties of Wei and Jin. The content is mainly the Buddhist concept which promote reincarnation and reality, and inevitable karma. Tang Lin in the preface says, "The preachings in the way of Shi are about causality. The reason is what we have done. And the result is what we have got. Any behaviors we have done have their results. And any results you we got have their reasons. The karma can be divided into three categories: The present karma, the living karma and the getting karma. And he also says, "The three karmas can control all the laws. Today I see them and I suddenly understand everything." The novels use plenty of resurrection themes to prove the Buddhist causality by expressing the things about resurrection. The novels not only contains Tang people's pondering on the ways of nature and man and the life noumenon and the best wishes about persuading people of the world to be good, but also presents with its unique circular structure the concept of the novel about Tang people's curiosity with care and going towards the ode. And it has great impact on the later classical novels 
and becomes the advocate of novels with the theme of the resurrection.

\section{ACKNOWLEDGEMENT}

One of the Achievements for the Rearch on the Narrative about the Dreamworld of Tang legends of the Scientific Research Project of the Education Department of Sichuan Province 12SB072 )

\section{REFERENCE}

[1] Tang Lin."The ancient novel series - Ming Bao Ji" proofreaded by Fang Shiming,Beijing: Zhonghua Book Company, 1992 edition, page second.
[2] The Collation and Annotation Made by Yuan Ke. The Collation and Annotation made by Shan Hai Jing (Supplemented and Revised Edition)[M]. Chengdu: Bashu Publishing House,1993, P258.

[3] Wrote by Carl gustav jung[Swiss], Translated by Xu Delin. The Archetypes and the Collective Unconsciousness[M].Beijing: International Culture Publishing Company, 2011 Edition, P91-92.

[4] Yang Yi.Chines Narratology[M]. Beijing: People's Publishing House, 1997 Edition, p38-39.

[5] He Xiguang.The Model for Conscious Oral History Works in Tang Dynasty, The Sanxia College Journal, the Sixth Periodical in 2006.

[6] Yang Yi. The Historical Theory of Chinese Classical Novels[M]. Beijing:China Social Sciences Publishing House, 1996. 